\title{
Evaluation of Spurious Readings in Los Alamos Personnel TL Dosimeters
}

\author{
Y. Eisen \\ G. J. Littlejohn \\ J. R. Cortez
}

This report was prepared as an account of work sponsored by an agency of the United States Government. Neither the United States Government nor any agency thereof, nor any of their employees, makes any warranty, exoress or implied, or assumes any legal liability or responsibility for the accuracy, completeness, or usefulness of any information, apparatus, product, or process disclosed, or represents that its use would not infringe privately owned rights. Reference herein to any specific commercial product, process, or service by trade name, trademark, manufacturer, or otherwise does not necessarily constitute or imply its endorsement, recorrmendation, or favoring by the United States Government or any agency thereof. The views and opinions of authors expressed herein do not necessarily state or reflect those of the United States Government or any agency thereof. 


\section{EVALUATION OF SPURTOUS READINGS \\ IN LOS ALAMOS PERSONNEL TL DOSIMETERS}

by

Y. Eisen, G. J. Littlejohn,

and J. R. Cortez

\section{ABSTRACT}

This study investigates the possibility of tritium build-up in TLD-600 chips irradiated with neutrons and the causes of spurious readings in the Harshaw TLD cards used for personnel dosimetry.

Experiments indicated that spurious readings in TLD-600 chips, previously irradiated with neutrons, might occur in cases where the cards had been accidentally read at temperatures lower than $300^{\circ} \mathrm{C}$ as a result of bad contact between the hot finger in the reading system and the chips. Because a TLD card contains glue and paper bar-code labels, the postannealing is performed at $80^{\circ} \mathrm{C}$ for 17 hours. This annealing procedure alone does not effectively deplete the high-energy traps, such as those near $260^{\circ} \mathrm{C}$, populated by high-LET (Linear Energy Transfer) particles. TLD-600 chips, irradiated on a phantom by $400 \mathrm{mrem}$ of moderated fission neutrons, read at $240^{\circ} \mathrm{C}$, annealed at $80^{\circ} \mathrm{C}$ for 17 hours, and then reread at $280^{\circ} \mathrm{C}$, showed residual doses as large as 200 mrem (equivalent photons).

Calculations and experiments show that for neutron exposures around 1 rem of moderated fission reutrons with an average energy of $500 \mathrm{keV}$, the maximum build-up of dose as a result of tritium formation is less than 1 mrem. The dose build-up in properly annealed TLD-600 and TLD-700 chips, is nearly the same, even though the TLD-600 chips were previously irradiated by neutrons. Both kinds of chips show natural background accumulation.

A mechanism for annealing the Harshaw cards at high temperatures, without destroying the label or the adhesive material, was developed and found to be useful. 


\section{INTRODUCTION}

In the past, spurious readings have been noticed in Harshaw TLD cards used as personnel dosimeters at the Los Alamos National Laboratory. 1 It was found that in some of these cases, the readings appeared in TLD-600 chips. The history of the chips showed that on many of these occasions, the cards had once been exposed to neutron dose equivalents up to 1 rem during routine usage.

The causes for spurious readings created by nonradiation scirces are the same for both TLD-600 and TLD-700 chips. The sources include mechanical stress, dirt, ultraviolet light, etc. ${ }^{2}$ Spurious readings caused by radiation might be more pronounced in TLD-600 chips than in TLD-700 chips. These readings can be caused by inappropriate postannealing of the irradiated chips or by tritium build-up in TLD-600 chips. When TLD cards are recycled in the reader many times without proper postannealing, appearance of spurious readings resulting from growth of the main peak is most probable. ${ }^{3}$

Measurements were carried out with single TLD chips to investigate the following:

- Is standard postannealing procedure at $80^{\circ} \mathrm{C}$ effective in erasing all effects resulting from previous irradiations?

- What are the residual doses remaining in TLD-600 and TLD-700 chips expgsed to neutrons and gamma rays, read at temperatures betwegn $240^{\circ}-200^{\circ} \mathrm{C}$, and then reread at higher temperatures between $280^{\circ}-$ $300^{\circ} \mathrm{C}$ ?

- Is there any significant dose build-up from tritium formation in TLD-600 chips exposed to about 1 rem of moderated fission neutrons. during 3 months of storage after reading and annealing?

This study also describes a system for annealing the Harshaw TLD cards without destroying their structure.

\section{THEORETICAL CONSIDERATIONS}

\section{A. The TLD Card}

The Harshaw dosimeter card consists of three TLD-700 chips and one TLD-600 chip. For their protection, the chips are sandwiched between Teflon foils, which are glued to the aluminum frame of the card. The card also includes a paper bar-code label. Neither the 
paper nor the glue can tolerate temperatures higher than $120^{\circ} \mathrm{C}$. The Teflon foils soften and melt above a temperature of about $300^{\circ} \mathrm{C}$.

B. Reading and Anneal ing Procedures

TLD-600 and TLD-700 chips behave similarly when irradiated by low-LET particles such as photons, and their glow curves are dominated by the $190^{\circ} \mathrm{C}$ peak. However, when TLD-600 chips are exposed to thermal neutrons, high-LET particles such as tritons and alpha particles, created in the reaction $6_{\mathrm{Li}}(n, \alpha)^{3} \mathrm{H}$, are responsible for the thermoluminescent effects. These high-LET particles also populate trapping states higher than $190^{\circ} \mathrm{C}$. A significant peak is shown at a temperature of about $260^{\circ} \mathrm{C} .4$

The trapped carriers are measured in the Harshaw reader by placing the TLD chips in contact with a hot finger that is progressively heated to $300^{\circ} \mathrm{C}$. This temperature is sufficient to deplete the traps filled either by the low- or high-LET particles. However, there might be occasions when the temperature of the hot finger is $300^{\circ} \mathrm{C}$, yet the chip is heated to a lower temperature. This can occur, for instance, when the hot finger is dirty or when the chip is displaced from its original position by repeated readings.

Thermoluminescent lithium fluoride chips need to be annealed in order to erase all effects caused by previous irradiations. Zimmerman et al. 5 proposed an annealing process of three steps:

$$
\begin{aligned}
& \text { 1. 1-hour heating at } 400^{\circ} \mathrm{C} \text {, } \\
& \text { 2. cooling at constant rate, } \\
& \text { 3. 20-hour storage at } 80^{\circ} \mathrm{C} \text {. }
\end{aligned}
$$

Slight modifications of this procedure are tolerable. The higher temperature anneal depletes all occupied traps and redistributes impurities and defects in the lattice. The lower temperature anneal results in rearrangement of the trapping levels.

Single TLD chips, used at Los Alamos for extremity dosimetry, are annealed at $400^{\circ} \mathrm{C}$ for 1 hour, then at $100^{\circ} \mathrm{C}$ for 2 hours, and then cooled rapidly. (This annealing procedure is denoted for further discussion as the standard $400^{\circ} \mathrm{C}$ procedure.) The only annealing used at Los Alamos for the Harshaw card is an $80^{\circ} \mathrm{C}$ bake-out for 17 hours. 
Utilization of this procedure is affected by limitations of the card mentioned in Section $A$; in addition, it will not sufficiently deplete the thermoluminescent traps at $190^{\circ} \mathrm{C}$ and is especially inadequate at higher trap temperatures such as $260^{\circ} \mathrm{C}$. The regular reading cycle of the Harshaw 2276 reader does not provide any of the effects caused by the standard $400^{\circ} \mathrm{C}$ procedure, especially for high doses.

C. Tritium Build-Up

Burgkhardt and $\mathrm{Piesch}^{6}$ indicate in a recent paper that the build-up of dose caused by the production of tritium is 43 mrem after 100 days of storage when the TLD-600 is exposed to 10 rem of thermal neutrons. Assuming that a worker is exposed to 1 rem of moderated fission neutrons with an average energy of $500 \mathrm{keV}$, the fraction of thermal albedo flux impinging the TLD-600 chip is about 10 percent of the incident flux. ${ }^{7}$ one rem of $0.5-\mathrm{MeV}$ neutrons corresponds to a flux of $4.3 \times 10^{7} \mathrm{n} / \mathrm{cm}^{2}$. Therefore, the thermal albedo flux returning from the body is $4.3 \times 10^{6} \mathrm{n} / \mathrm{cm}^{2}$. This flux corresponds to about 4.3 mrem of thermal neutrons. On the basis of Reference 2 , after 100 days of storage, this thermal exposure leads to a build-up of dose due to tritons of $1.85 \times 10^{-2} \mathrm{mrad}$.

The dose build-up can also be estimated by calculating the number of electrons (beta particles) produced in the TLD-600 chip during 100 days of storage after annealing when the chip is exposed to 4.3 mrem of thermal neutrons. The calculation, based on energy deposition, will not be accurate because the thermal neutrons are highly attenuated when passing through the TLD-600 chip and also because the ranges of the beta particles ( $E_{\max }=18 \mathrm{keV}$ ) are significantly smaller than the chip dimensions. These factors lead to a dose which is not uniformly distributed in the chip. A thickness of $29 \mathrm{mg} / \mathrm{cm}^{2} 6$ LiF absorbs half of tine thermal neutron flux. (The thickness of the TLD-600 chip is $210 \mathrm{mg} / \mathrm{cm}^{2}$ ) Assuming that the average energy of the beta particle is $6 \mathrm{keV}$ and that all albedo thermal neutrons are absorbed, the total energy deposited is less than 0.2 mrad during 100 days of storage. 


\section{EXPERTMENTS AND RESULTS}

\section{A. Selection of Equally Responding Chips}

A batch of 80 single TLD-700 chips was exposed to $1800 \mathrm{mR}$ of ${ }^{137}$ Cs gamma rays. Another batch of 90 single TLD -600 chips, mounted on a polyethylene phantom $30 \times 30 \times 15 \mathrm{~cm}^{3}$, was exposed to $150 \mathrm{mrem}$ neutrons of ${ }^{252} \mathrm{Cf}$ moderated by a 30 -cm-diameter $D_{2} \mathrm{O}$ sphere. Before irradiation, all chips were annealed by the standard $400^{\circ} \mathrm{C}$ procedure. The chips were read in an Eberline TLR-5 reader set, at a temperatire of $280^{\circ} \mathrm{C}$, and those chips with a light output within $1 \sigma( \pm 10 \%)$ from the average reading were used for these experiments. The light output of the TLD-600 chips irradiated in the above manner was equivalent to approximately $800 \mathrm{mR}$ of garma rays.

B. Comparison of $400^{\circ} \mathrm{C}$ and $80^{\circ} \mathrm{C}$ Annealing Procedures

All chips were again annealed with the standard $400^{\circ} \mathrm{C}$ procedure. Then some of the TLD -700 chips were exposed to $1800 \mathrm{mR}$ of ${ }^{137} \mathrm{Cs}$ gamma rays, and the TLD-600 chips were exposed on a phantom to 400 mrem of neutrons from a moderated ${ }^{252} \mathrm{Cf}$ source. The remainder of the TLD-600 and TLD-700 chips were used as background controls. All chips were read in an Eberline TLP.-5 reader for 12 seconds at a $100^{\circ} \mathrm{C}$ preheat period and then for 14 seconds at $240^{\circ} \mathrm{C}$. The reader was calibrated so that $1 \mathrm{mR}$ was approximately equal to 1 integrating charge unit.

Without rereading the chips at a temperature higher than $240^{\circ} \mathrm{C}$, (i.e., $280^{\circ} \mathrm{C}$ ) the chips were then divided into eight groups. Groups 1 and 2 included previously read unirradiated TLD-600 and TLD-700 chips, and groups 3 and 4 included previously read TLD-600 and TLD-700 chips irradiated with $400 \mathrm{mrem}$ of neutrons and $1800 \mathrm{mR}$ of gamma rays, respectively. Groups $5,6,7$, and 8 were identical to groups $1,2,3$, and 4 , respectively.

Groups 1 through 4 were then annealed by the standard $400^{\circ} \mathrm{C}$ procedure, and groups 5 through 8 were annealed at $80^{\circ} \mathrm{C}$ for 17 hours. The chips were then reread in the $T L R-5$ reader at $280^{\circ} \mathrm{C}$; the residuals are summarized in Table $I$. All chips were annealed again by the standard $400^{\circ} \mathrm{C}$ procedure and, again, TLD-600 chips were irradiated on a phantom to $400 \mathrm{mrem}$ moderated ${ }^{252} \mathrm{Cf}$ neutrons. The TLD-700s were irradiated with $1800 \mathrm{mR}{ }^{137} \mathrm{Cs}$ gamma rays. However, this time the chips were read at $260^{\circ} \mathrm{C}$ in a Harshaw $2000 \mathrm{C}$ reader that 
was calibrated so that $1 \mathrm{mR}$ is approximately equal to 1 integrating charge unit. After being read, the chips were divided into eight groups (as previously described) of which four groups were postannealed by the regular $400^{\circ} \mathrm{C}$ procedure and four groups were annealed at $80^{\circ} \mathrm{C}$. The chips were then reread at $280^{\circ} \mathrm{C}$, the residuals are summarized in Table II.

Tables I and II show that the annealing at $80^{\circ} \mathrm{C}$ is not effective either for TLD -600 or TLD-700 chips if some residuals are left over after reading either at $240^{\circ} \mathrm{C}$ or $260^{\circ} \mathrm{C}$. The residuals are especially significant for TLD-600 chips irradiated with neutrons. Residuals left over in the TLD $-600 \mathrm{chips}$ that are read at $240^{\circ} \mathrm{C}$ are larger than those read at $260^{\circ} \mathrm{C}$. Also, the fluctuations of the residuals for irradiated TLD-600 chips are larger than for those of irradiated TLD-700 chips.

C. Comparison Between $400^{\circ} \mathrm{C}, 300^{\circ} \mathrm{C}$, and $80^{\circ} \mathrm{C}$ Annealing Procedures on TLD-600 Chips

TLD-600 chips that were irradiated with 400 mrem of neutrons and read at $240^{\circ} \mathrm{C}$ were divided into three groups. The first group was postannealed with the standard $400^{\circ} \mathrm{C}$ procedure; the second group was postannealed at $80^{\circ} \mathrm{C}$ for 17 hours; and the third group was postannealed at $300^{\circ} \mathrm{C}$ for 2 hours, then at $100^{\circ} \mathrm{C}$ for 2 hours, and then cooled rapidly to room temperature. All of the TLD chips were then read in the $T L R-5$ reader at a temperature of $280^{\circ} \mathrm{C}$. The residuals are sumiarized in Table III. It can be observed that the residuals might be as large as $170 \mathrm{mR}$ gamma equivalent when TLD-600 chips irradiated with 400 mrem neutrons are read at a temperature of $240^{\circ} \mathrm{C}$ and then annealed at $80^{\circ} \mathrm{C}$. The residuals after annealing at $400^{\circ} \mathrm{C}$ or at $300^{\circ} \mathrm{C}$ were consistent with background.

D. Dase Build-Up Caused by Tritium in TLD-600 Chips

The TLD-600 and TLD-700 chips used in the previous experiments (read and annealed several times) were used to measure the dose build-up caused by tritium. Some of these TLD-600 and TLD-700 chips have been exposed during previous experiments to 950 mrem of moderated fission neutrons and to approximately $5 \mathrm{R}$ of ${ }^{137} \mathrm{Cs}$ gamma rays, respectively. The remaining TLDs were used for background control. 
TABLE I

LIGHT OUTPUT

(Reading at $240^{\circ} \mathrm{C}$ and Rereading at $280^{\circ} \mathrm{C}$, Reader Dark Current is $17 \pm 1$ )

\begin{tabular}{|llll|}
\hline \multicolumn{4}{c}{$400^{\circ} \mathrm{C}$ Anneal Ing } \\
\hline $\begin{array}{l}\text { TLD-600 } \\
\text { Background }\end{array}$ & TLD-700 & GROUP 3 & GROUP 4 \\
\hline $19 \pm 1$ & $\begin{array}{l}\text { TLD-600 } \\
\text { Previously } \\
\text { Irradiated }\end{array}$ & $\begin{array}{l}\text { TLD-700 } \\
\text { Previous } 1 \mathrm{y} \\
\text { Irradiated }\end{array}$ \\
\hline
\end{tabular}

$80^{\circ} \mathrm{C}$ Annealing

\begin{tabular}{|llll|}
\hline GROUP 5 & GROUP 6 & GROUP 7 & GROUP 8 \\
\hline TLD-600 & TLD-700 & TLD-600 & TLD-700 \\
Background & Background & $\begin{array}{l}\text { Previously } \\
\text { Irradiated }\end{array}$ & $\begin{array}{l}\text { Previously } \\
\text { Irradiated }\end{array}$ \\
\hline $18 \pm 1$ & $22 \pm 1$ & $126 \pm 22$ & $32 \pm 2$ \\
\hline
\end{tabular}




\section{TABLE II}

\section{LIGHT OUTPUT}

(Reading at $260^{\circ} \mathrm{C}$ and Rereading at $280^{\circ} \mathrm{C}$, Reader Dark Current is $4 \pm 1$ )

$400^{\circ} \mathrm{C}$ Annealing

\begin{tabular}{|llll|}
\hline GROUP 1 & GROUP 2 & GROUP 3 & GROUP 4 \\
\hline $\begin{array}{l}\text { TLD-600 } \\
\text { Background }\end{array}$ & $\begin{array}{l}\text { TLD-700 } \\
\text { Background }\end{array}$ & $\begin{array}{l}\text { TLD-600 } \\
\text { Previously } \\
\text { Irradiated }\end{array}$ & $\begin{array}{l}\text { TLD-700 } \\
\text { Previous } 1 y \\
\text { Irradiated }\end{array}$ \\
\hline $11 \pm 1$ & $10 \pm 1$ & $12 \pm 1$ & $10 \pm 1$ \\
\hline
\end{tabular}

$80^{\circ} \mathrm{C}$ Annealing

\begin{tabular}{|llll|}
\hline GROUP 5 & GROUP 6 & GROUP 7 & GROUP 8 \\
\hline $\begin{array}{ll}\text { TLD-600 } \\
\text { Background }\end{array}$ & $\begin{array}{l}\text { TLD-700 } \\
\text { Background }\end{array}$ & $\begin{array}{l}\text { TLD-600 } \\
\text { Previously } \\
\text { Irradiated }\end{array}$ & $\begin{array}{l}\text { TLD-700 } \\
\text { Previously } \\
\text { Irradiated }\end{array}$ \\
\hline $10 \pm 1$ & $9 \pm 1$ & $25 \pm 4$ & $12 \pm 1$ \\
\hline
\end{tabular}


TABLE III

Dose (TLD -600 chips) in $m$ Rem

(Reading at $240^{\circ} \mathrm{C}$ and Rereading at $280^{\circ} \mathrm{C}$ )

\begin{tabular}{|l|l|l|}
\hline $80^{\circ} \mathrm{C}$ Annealing & $300^{\circ} \mathrm{C}$ Anneal ing & $400^{\circ} \mathrm{C}$ Annealing \\
\hline $\begin{array}{c}(170 \pm 18) \\
\text { (Gamma Equivalent) }\end{array}$ & Background & Background \\
\hline
\end{tabular}

All chips were first annealed with the standard $400^{\circ} \mathrm{C}$ procedure and then separated into four groups. The first two groups included the background control TLD-600 and TLD-700 chips, and the other two groups included the TLD-600 and TLD-700 chips exposed to 950 mrem neutrons and $5 \mathrm{R}$ gamma rays, respectively.

A separate group of TLD-700 chips was annealed by the standard $400^{\circ} \mathrm{C}$ procedure and was used to control the stability of the reading system during the 3-month period of measurements after the annealing. This group of TLD-700 chips was divided into three subgroups. One group was not irradiated and was left for background control. The other two groups were irradiated with $1300 \mathrm{mR}{ }^{137} \mathrm{Cs}$ and $1000 \mathrm{mR}{ }^{60} \mathrm{Co}$ gamma rays, respectively. The dose build-up was measured during 3 months after the above annealing.

During the measurement period, five readings were carried out on chips from the seven groups mentioned above. Reading temperature was $240^{\circ} \mathrm{C}$ to decrease the infrared noise. The signal was not affected by decreasing the hot finger temperature. Between measurements, unread chips were kept in a nonradiation area. Figure 1 displays the net dose of previously irradiated TLD-600 and TLD-700 chips as a function of the days passed after annealing. The accumulated dose is defined in the following way:

$$
\text { Dose }(m R)=\frac{(\text { Chip reading-Dark current) }}{\text { Reader calibration (count/mR) }}
$$


The reader calibration in counts/mR was determined by reading TLD-700 chips irradiated with ${ }^{137} \mathrm{Cs}$ and ${ }^{60} \mathrm{Co}$ gammá rays.

One can observe that the behavior of dose bulld-up with time is almost identical for TLD-600 and TLD-700 chips. The statistical uncertainty at each point is estimated to be $\pm 20 \%$ where the largest difference between the two types of chips is 15\%. Figure 2 shows the differences in readings between chips previously irradiated and previously nonirradiated as a function of days passed after annealing. The differences are similar for TLD-600 and TLD-700 and they are consistent with zero. (Experimental uncertainty of the first point represents uncertainties of the other points.) Figures 3 and 4 show the natural background build-up during storage measured with nonirradiated TLD-700 chips of the working batch and of the control batch. The results obtained from both batches are consistent
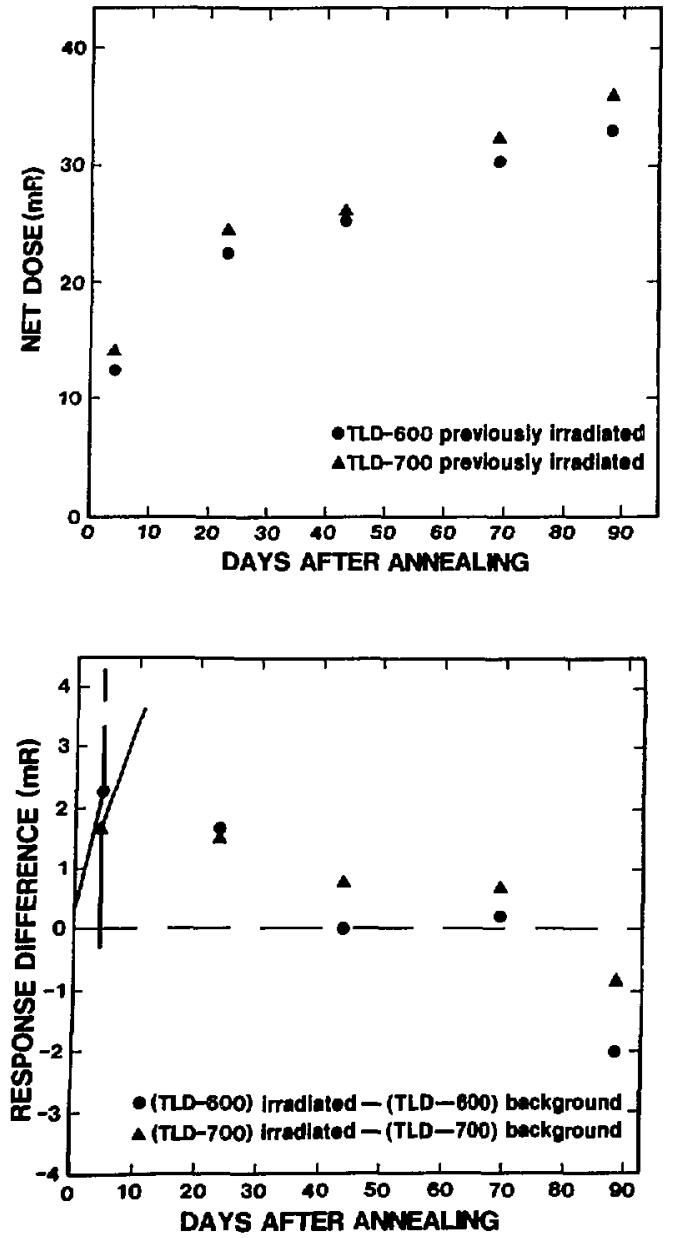

Fig. 1. Dose build-up of TLD-600 and TLD-700 chips as a function of storage time after annealing. Before annealing, the chips were irradiated to about $1 \mathrm{rem}$ of ${ }^{252} \mathrm{Cf}$ neutrons moderated by $\mathrm{D}_{2} \mathrm{O}$ and to about $5 \mathrm{R}$ of $137 \mathrm{Cs}$ gamma rays, respectively.

Fig. 2. Dose differences between reading of chips irradiated before annealing and nonirradiated chips as a function of storage time after annealing. Dose differences are displayed for both TLD-600 and TLD-700 chips. 


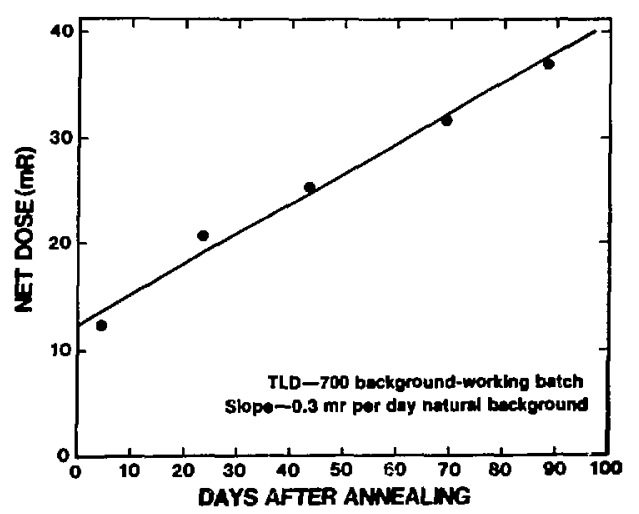

Fig. 3. Dose build-up in TLD-700 chips used to control the background in the working batch given as a function of storage time after annealing.

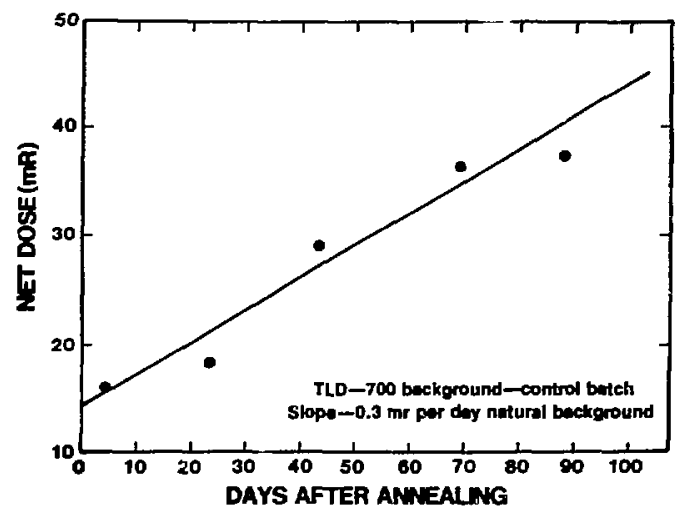

Fig. 4. Dose build-up in TLD-700 chips of the control group given as a function of storage time after annealing.

with each other and give a natural background of $0.030 \pm 0.04 \mathrm{mR} /$ day.

IV. ANNEALING SYSTEM FOR HARSHAW TLD CARDS

The annealing procedure proposed by Zimmerman et al. 5 is not applicable to Harshaw TLD cards. First, since the chips are sandwiched between Teflon layers, the anneal cannot be performed at temperatures higher than about $300^{\circ} \mathrm{C}$. At higher temperatures, the Teflon will soften or melt, and the optical properties will be dramatically changed. Second, the adhesive material present in the card and the bar-code label prevent heating the entire card above $120^{\circ} \mathrm{C}$.

A prototype system for annealing the Harshaw TLD cards was built and tested. The system heats the TLD chips homogeneously to $300^{\circ} \mathrm{C}$ for 12 minutes, while the remainder of the card is maintained at a temperature lower than $120^{\circ} \mathrm{C}$. This differential heating is achieved by covering the TLD card, except for the chip area, with an insulating material and by thermally attaching a brass water-cooling jacket to the card. Heat is supplied by hot air flow and two temperature sensors are used. The first is in contact with one of the chips and the other is in contact with the aluminum frame of the card. The two sensors assure that the temperatures 
in the chis areas and the aluminum frame are not increased beyond $300^{\circ} \mathrm{C}$ and $120^{\circ} \mathrm{C}$, respectively.

The prototype system was tested with four Harshaw cards, which were exposed both to the $1 \mathrm{R}$ of ${ }^{137} \mathrm{Cs}$ gamma rays and (on a phantom) to $150 \mathrm{mrem}$ of $\mathrm{D}_{2} \mathrm{G}$-moderated fission neutrons. The cards were then annealed as described above and then read with the Harshaw 2276 system. The residual doses were consistent with background. This procedure was repeated several times with reproducible results. Additional experiments indicated that the sensitivity of the chips did not change with repeated annealings, although the results obtained are preliminary and further tests will be condlicted.

\section{SUMMARY AND CONCLUSIONS}

The experiments show that if irradiated TLD-500 or TLD-700 chips are accidentally read at temperatures lower than $300^{\circ} \mathrm{C}$ in the Harshaw 2276 reader, annealing at $80^{\circ} \mathrm{C}$ for 17 hours does not effectively deplete the high-energy traps (for instance, at $190^{\circ} \mathrm{C}$ or at $260^{\circ} \mathrm{C}$ ). This annealing procedure is, in particular, not effective for depleting the high-energy traps of TLD-600 chips that are filled by high-LET particles formed by the $6_{L i(n, \alpha)}{ }^{3} \mathrm{H}$ reaction.

TLD -600 chips, mounted on a phantom and irradiated with 400 mrem of ${ }^{252} \mathrm{Cf}$ neutrons moderated by a 30-cm-diameter $D_{2} \mathrm{O}$ sphere, might show residuals as large as $200 \mathrm{mR}$ (gamma equivalent) if first read at $240^{\circ} \mathrm{C}$ and then reread at high temperatures between $280-300^{\circ} \mathrm{C}$.

The experiments also show that the build-up of dose in TLD-600 chips, caused by tritium formation resulting from neutron exposures around 1 rem of moderated fission neutrons, is less than 1 mrad during the 3 months following annealing. The dose build-up, after high-temperature annealing, in TLD -600 and TLD-700 chips previously irradiated or nonirradiated is nearly the same and shows natural background of the order of $0.3 \mathrm{mR} / \mathrm{day}$.

In conclusion, in order to avoid spurious readings, TLD chips should be annealed at high temperatures near $300^{\circ} \mathrm{C}$ and then be annealed at $80^{\circ} \mathrm{C}$ for 17 hours.

A method for annealing the Harshaw cards at high temperatures near $300^{\circ} \mathrm{C}$ without destroying the label or the adhesive material was developed and found to be useful. 


\section{REFERENCES}

1. E. Storm, P. L. Buslee, A. W. Blackstock, G. J. Littlejohn, J. R. Cortez, R. V. Fultin, and J. N. P. Lawrence, "The Los Alamos Thermoluminescence Dosimeter Badge," Radiat. Prot. Dosin. 1, 209 (1981).

2. J. R. Cameron, N. Suntharanl ingam, and G. N. Kenney, Thermoluminescent Dosimetry (University of Wisconsin Press, Madison, 1968).

3. L. F. Booth, T. L. Johnson, and F. H. Attix, "Lithium Fluoride Glow Peak Growth Duc to Annealing," Heal th Phys. 23, 137 (1972).

4. K. Becker, Solid State Dosimetry, (CRC Press, Cleveland, Ohio 1973) and references therein.

5. D. W. Zimmerman, C. R. Rhyner, and J. R. Cameron, "Thermal Annealing Effects on the Thermoluminescence of Lithium Fluoride," Health Phys. 12, 525 (1966).

6. B. Burgkhardt and E. Piesch, "Estimation of the Build-up of Zero Dose Reading in LiF Thermoluminescence Dosineters Due to Neutron Produced Tritium," Radiat. Prot. Dosim. 2, 105 (1982).

7. R. C. Alsmiller and J. Barish, "The Calculated Response of ${ }^{6}$ LiF Albedo Dosimeters," Heal th Phys. 26, 13 (1974). 